\title{
Palliative Senning Procedure: Management of dTGA with VSD and PVOD in an Adolescent
}

\author{
Amitabh Satsangi ${ }^{*}$, Biswajit Singh ${ }^{2}$ \\ ${ }^{1}$ Department of Cardiothoracic and Vascular Surgery, All India Institute of Medical Sciences, New Delhi, India \\ ${ }^{2}$ Department of Surgical Disciplines, All India Institute of Medical Sciences, New Delhi, India \\ Email: *amoeba418@gmail.com
}

How to cite this paper: Satsangi, A. and Singh, B. (2020) Palliative Senning Procedure: Management of dTGA with VSD and PVOD in an Adolescent. World Journal of Cardiovascular Surgery, 10, 150-157. https://doi.org/10.4236/wjcs.2020.108018

Received: July 17, 2020

Accepted: August 14, 2020

Published: August 17, 2020

Copyright $\odot 2020$ by author(s) and Scientific Research Publishing Inc. This work is licensed under the Creative Commons Attribution International License (CC BY 4.0).

http://creativecommons.org/licenses/by/4.0/

\begin{abstract}
Patients with D-TGA with atrial level mixing of systemic and pulmonary blood, the morphological left ventricle supports the low pressure pulmonary circulation and regresses in mass and volume as time passes. The LV once regressed is unable to support the high pressure systemic circulation after ASO. These patients are candidates for early ASO, preferably within 3 weeks of life. As age progresses, the scope of these surgical procedures skews and an atrial switch remains the only option to improve quality of life. In Atrial switch, the pulmonary and systemic circulation is returned into an "in series" circulation and cyanosis is obliterated.
\end{abstract}

\section{Keywords}

Atrial Switch, Palliation, Pediatric Cardiac Surgery

\section{Introduction}

The birth prevalence of congenital heart disease (CHD) is reported to be 8 12/1000 live births [1].

Complete transposition of the great arteries (D-TGA) represents approximately $5 \%-8 \%$ of CHD and accounts for $25 \%$ of deaths in the first year of life [2].

Arterial switch operation (ASO) has revolutionized the management of D-TGA and has been able to bring the down the mortality to $2 \%$ - 3\% [3] [4] after surgery, reduced requirement for re-interventions, and provide good quality of life to these patients.

In D-TGA, the pulmonary and systemic circulations are two parallel circuits and the survival of patient is dependent on the mixing between the two and the amount of pulmonary blood flow. 
D-TGA is broadly classified into those with ventricular septal defect (VSD) and those without.

About $40 \%-50 \%$ cases of D-TGA are associated with ventricular septal defect [5].

The LV once regressed will be unable to support the high pressure systemic circulation after ASO. These patients are candidates for early ASO, preferably within 3 weeks of life.

However as age progresses, the scope of surgical procedures skews and an atrial switch remains the only option to improve quality of life.

By an atrial switch, the pulmonary and systemic circulation is returned into an "in series" circulation and cyanosis is obliterated. However, right ventricle (RV) remains the systemic ventricle and ultimately fails to support the high pressure systemic circulation after many years.

In D-TGA with a large VSD, since LV is exposed to systemic pressure, the LV does not regress. However, continuous exposure to increased pulmonary flow causes accelerated pulmonary vascular disease and eventually severe or irreversible pulmonary vascular hypertension (PAH) [6] [7] [8].

Postoperative course in patient with severe or suprasystemic PAH after ASO is stormy and often requires prolonged ventilator support [9]. In these patients, $\mathrm{RV}$ is unable to support the high pressure pulmonary circulation and results in PAH crises or cardiac failure.

Atrial switch with or without closure VSD remains the palliative procedure of choice in this subset of patients, which improves quality of life by decreasing cyanosis.

Unfortunately in our country many patients with D-TGA, go undetected for months, or sometimes years, and when they do reach the tertiary care center, either it is too late or it is too difficult to decide about the suitability for surgical correction. Palliative atrial switch (PAS) procedures that reroute pulmonary and systemic venous drainage and leave a ventricular septal defect (VSD) open have been used in the treatment of this subset of deeply cyanotic patients who have severe pulmonary vascular obstructive disease (PVOD) [10].

We present a case report of a patient of D-TGA with vsd and pulmonary vascular obstructive disease managed with a palliative senning procedure.

\section{Case Report}

A 12-year-old male patient presented to outpatient clinic with complaints of 5 episodes of small amount hemoptysis along with dyspnoea on exertion (NYHA I progressing to NYHA III) palpitation on exertion present. Patient had episodes of frequent LRTI episodes for last 5 years.

Patient was diagnosed with complex congenital heart disease at 1 year of age and patient stopped attending clinics.

Patient had received treatment for LRTI 5 months back but currently having no medication. 
On physical examination, patient had no pallor but cyanosis and clubbing. On repiratory system evaluation $\mathrm{B} / \mathrm{L} \mathrm{AE}(+)$ with NVBS without added sounds were found out. Basal $\mathrm{SpO}_{2}$ was $71 \%$.

$\mathrm{SpO}_{2}$ on exertion and after 10 min $\mathrm{O} 2$ supply were $72 \% \& 80 \%$ respectively.

All pulses were well palpable. S1 and S2 were normal with a wide and fixed split along with a loud P2. ESM 2/6 at LPSA \& MDM 3/6 at Apex. Other systems were NAD.

Transthoracic echocardiography confirmed atrioventricular concordance, VA discordance, and a large sub pulmonic ventricular septal defect with severe pulmonary artery hypertension with normal biventricular function.

Hematological evaluation revealed hemoglobin of $22.3 \mathrm{mg} / \mathrm{dl}$ and hematocrit of 66.9 .

Chest $\mathrm{x}$-ray (Figure 1(1)) there were features of cardiomegaly and pulmonary arterial hypertension.

CT CARDIAC ANGIOGRAPHY (Figure 1(2)) d TGA, subpulmonic large VSD, dilated confluent pulmonary arteries with right ventricular hypertrophy.

Cardiac catherization was performed which revealed (Figure 1(3)).

d-TGA, large S/P VSD, severe PAH,B/L confluent good sized pulmonary artery with normal biventricular function, Post OXGEN STUDY with 10 mins of high flow oxygen-BASAL QP/QS WAS 1.4 WITH PVRI/SVRI OF 0.7 WITH PVRI = 18.6 with POST OXYGEN Qp/Qs -18 of and Final diagnosis: PVRI/SVRI of 0.1 with PVRI $=2.4$ (Table 1$)$.

\section{Operative Procedure}

Surgical approach was via a standard median sternotomy. The pericardium was opened in the midline. The external cardiac anatomy was consistent with a diagnosis of d-TGA with sub-pulmonic vsd with severe PAH with the usual coronary artery pattern (1LCx $2 \mathrm{R})$. After systemic heparinization, moderately hypothermic $\left(28^{\circ} \mathrm{C}\right)$ cardiopulmonary bypass $(\mathrm{CPB})$ was established by cannulating the aorta and the extrapericardial parts of the superior (SVC) and inferior (IVC)

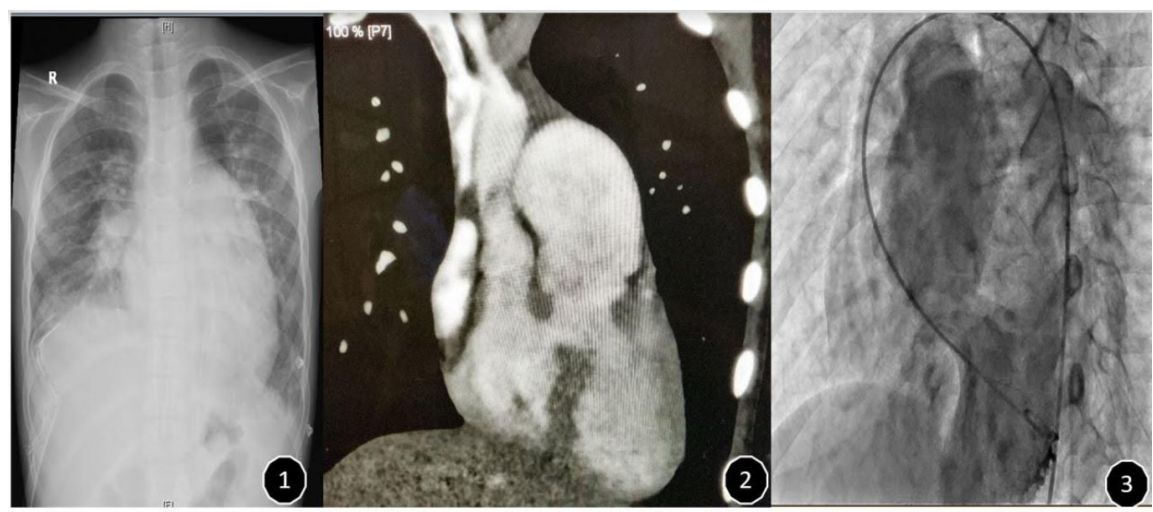

Figure 1. (1) Chest Xray-Cardiomegaly and features of pulmonary artery hypertension; (2) CT CARDIAC-dTGA, with VSD with enlarged pulmonary artery; (3) Catherization angiogram-Left ventricle communicating with pulmonary artey via a VSD. 
Table 1. Cardiac catheterization data.

\begin{tabular}{ccccc}
\hline Site & $\begin{array}{c}\text { Basal } \\
\text { saturation (\%) }\end{array}$ & $\begin{array}{c}\text { Saturation on } \\
\text { F102-100 Oxygen } \\
(\%)\end{array}$ & $\begin{array}{c}\text { Basal Pressure Data } \\
\text { (Mean mmHg) }\end{array}$ & $\begin{array}{c}\text { Pressure Data on } \\
\text { Oxygen (Mean } \\
\text { mmhg) }\end{array}$ \\
\hline $\begin{array}{c}\text { Superior vena cava } \\
\text { Right atrium }\end{array}$ & 42 & 55 & 4 & 5 \\
Right ventricle & 56 & & & 93 \\
Pulmonary artery & 88 & 98 & 96 & 7 \\
Left atrium & & & 6 & 100 \\
Left ventricle & 95 & 73 & 102 & \\
Aorta & 56 & & 99 & \\
Femoral artery & & & &
\end{tabular}

Cardiacindex 3.5, on oxygen; PVRt 186 Wood units on room air, 2.4 Wood units on oxygen; SIR/. 28.4 Wood units on room air, 32.3 on oxygen; OR: 4.9 on room air, 357 on oxygen; 2 s 3.5 on room air, 3.0 on oxygen; gp: Os: 1.4 on room air, 12.2 on oxygen.; P $\sqrt{ }$ R/SVR: 0.7 on room air, 0.1 on oxygen.

vena cava using right-angled venous cannula. Extra-pericardial cannulation of the SVC and IVC was preferred to facilitate the construction of the pulmonary venous baffle using in situ pericardium. Using electrocautery, a plane of dissection was developed between the right atrium (RA) and the pulmonary veins into the interatrial groove to expose the left atrium (LA).

After cross-clamping the aorta and delivering cardioplegia, the RA was opened $5 \mathrm{~mm}$ parallel to the atrioventricular groove and stay sutures were placed on both lips of the right atriotomy. The interatrial septum was laid open (Figure $2(1)$ ), through which the mitral valve and pulmonary veins were visualized. The coronary sinus was identified and completely laid open toward the LA. The LA was now opened on the right side and its edges were completely excised up to the entry of the right-sided pulmonary veins so that opening draining the pulmonary venous blood into the pericardial cavity was large and unobstructed. Following this, a systematic reconstruction of various pathways was accomplished in three layers as follows. The purpose of the first layer was to separate the pulmonary veins from the mitral valve and to direct the pulmonary venous return toward the opening in the LA. Working through the RA, this was accomplished by suturing a $3 \times 3-\mathrm{cm}$ patch of Dacron to the left atrial wall anterior to the left pulmonary veins and posterior to the left atrial appendage and below and behind the mitral valve with a continuous 4-0 polypropylene suture (Figure 2(2)). This patch therefore formed the posterior wall of the systemic venous pathway.

The purpose of the second layer was to create the systemic venous baffle and direct the SVC and IVC return toward the mitral valve. This was accomplished by suturing the right edge of the right atriotomy to the left margin of the ASD with a continuous 4-0 polypropylene suture (Figure 2(3), Figure 2(4)).

The purpose of the third layer was to create the pulmonary venous chamber with an aim to direct the pulmonary venous return toward the tricuspid valve. 


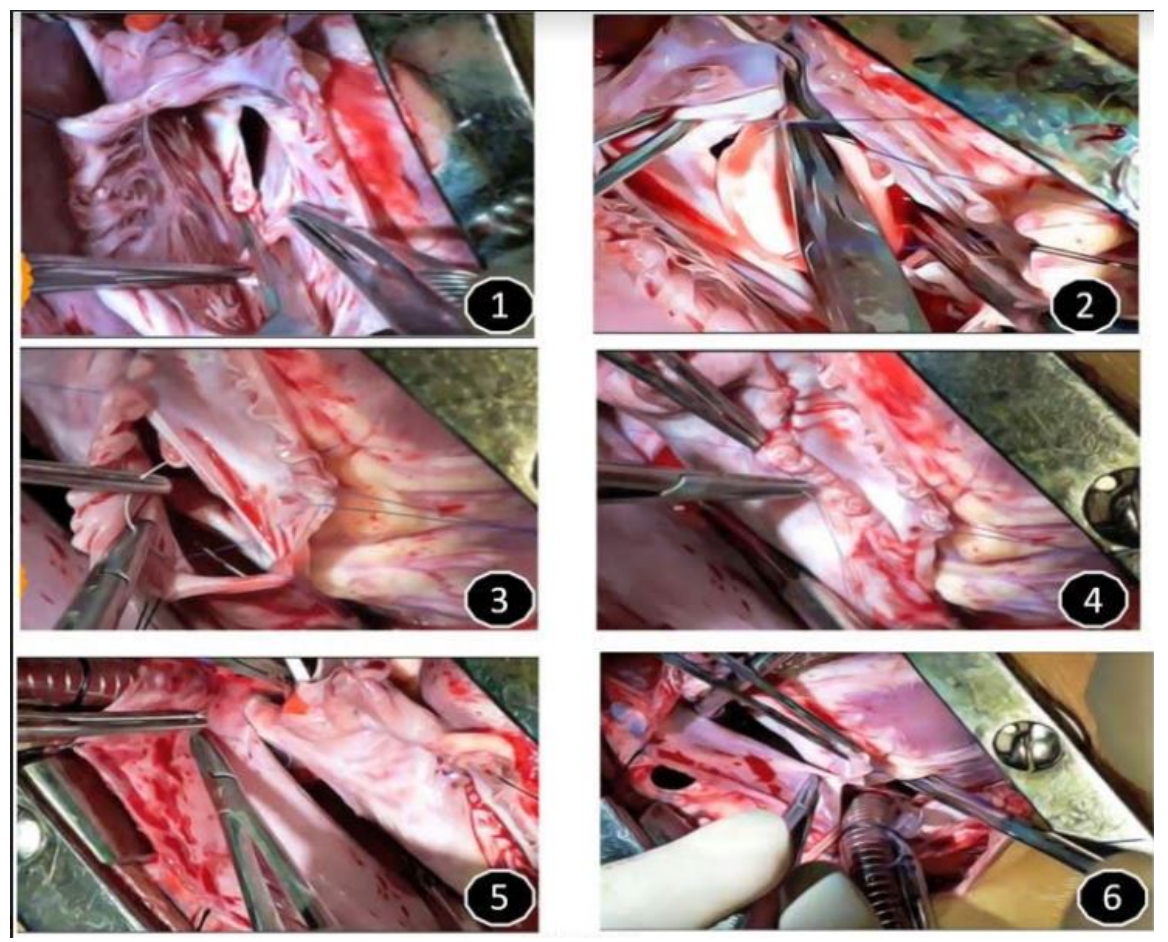

Figure 2. (1) Inter-atrial septum is divided; (2) Dacron patch is sutured behind the mitral valve; (3), (4) Atrial septum is approximated to right atrium routing svc and IVC to mitral valve; (5), (6) Approximation of right atrial wall to pericardium to route pulmonary veins to tricuspid valve.

The pericardium on the right side was sutured to the left edge of the right atriotomy so that was approximated with a continuous 4-0 polypropylene suture. As a result, the pulmonary venous return exited from the opening in the LA into the pericardial well and was directed toward the tricuspid valve through the pulmonary venous baffle (Figure 2(5), Figure 2(5)).

The sub-pulmonic ventricular septal defect was left open in view of the severe pulmonary hypertension. Once the reconstruction was completed, the aortic cross-clamp was released and after re-warming, the patient was uneventfully weaned off $\mathrm{CPB}$ with elective inotropic supports. Postoperative recovery was uneventful with systemic saturation of $100 \%$ and pO2 in excess of $100 \mathrm{mmHg}$.

Postoperative echocardiograms have revealed unobstructed systemic and pulmonary venous baffles and normal ventricular function.

\section{Discussion}

In 1958, Ake Senning performed with success the proposal suggested by Albert, performing the correction at the atrial level using autogenous atrial tissue to construct intracardiac baffles [11].

Dr. Adib Jatene described the ASO for correction of TGA in the neonatal pe$\operatorname{riod}[12]$.

Arterial switch operation with its concept of anatomical and physiological correction largely replaced the atrial switch procedures which were inferior to 
arterial switch operation on conceptual basis and inferior long term results and quality of life [13].

The arterial switch operation's supremacy has been corroborated by long-term results that show preservation of good left ventricular function, sinus rhythm and a low mortality with a survival rate of $88 \%$ at both 10 and 15 years [14].

In our country, however, complex congenital cardiopathies are diagnosed late, often presenting in advanced stages with severe pulmonary hypertension [15]. With the manifestation of severe pulmonary hypertension in patients with transposition of great vessels and associated lesions like vsd or large PDA who present late, total correction of the anomaly does not offer the same results as early surgery offers [9].

Patients presenting with severe pulmonary hypertension are better managed with a palliative atrial switch procedure with deals with performing a switch at the atrial level and leaving or creating a shunt in the form of ventricular septal defect for unloading of the subpulmonary ventricle [16].

Our patient who was diagnosed with dTGA with VSD at the age of 1 year presented at the age of 13 years for management, at the time of presentation the patient presented with a regressed left ventricle with severe pulmonary hypertension and definitive repair was not feasible.

Decision was taken to perform a palliative senning procedure in order to alleviate the cyanosis and morbidity of the patient.

In 1972, Lindesmith et al. described eight patients who had had a palliative Mustard operation.

They reported that in patients with transposition of the great arteries, ventricular septal defect and severe pulmonary vascular obstructive disease who underwent this operation, "the clinical improvement has been startling, and the morbidity resulting from these operations has been minimal" [17].

Penha et al. in their study in 2015 conclude "the palliative Senning procedure improved arterial oxygen saturation, reduced polycythemia, and provided a better quality of life to patients with TGA and VSD or Taussig-Bing DORV who had severe $\mathrm{PH}$, were considered inoperable, and had a poor prognosis" [16].

There are no clear guidelines for management of patients with TGA VSD with POVD due to late presentation and palliative atrial switch procedure offers a good management strategy with acceptable results.

With the review of literature and our case, it can be concluded that palliative senning procedure is a good management option for patients presenting with dTGA, VSD with severe pulmonary hypertension.

\section{Funding}

No funding source.

\section{Ethical Approval}

Not applicable. 


\section{Human Rights}

Not applicable.

\section{Consent}

Appropriate consent from the patient's family was taken.

\section{Conflicts of Interest}

No conflict of Interests.

\section{References}

[1] Hoffman, J.I. (2013) The Global Burden of Congenital Heart Disease. Cardiovascular Journal of Africa, 24, 141-145. https://doi.org/10.5830/CVJA-2013-028

[2] Liebman, J., Cullum, L. and Belloc, N.B. (1969) Natural History of Transposition of the Great Arteries: Anatomy and Birth and Death Characteristics. Circulation, 40, 237-262. https://doi.org/10.1161/01.CIR.40.2.237

[3] O’Brien, S.M., Clarke, D.R., Jacobs, J.P., Jacobs, M.L., Lacour-Gayet, F.G., Pizarro, C., et al. (2009) An Empirically Based Tool for Analyzing Mortality Associated with Congenital Heart Surgery. The Journal of Thoracic and Cardiovascular Surgery, 138, 1139-1153. https://doi.org/10.1016/j.jtcvs.2009.03.071

[4] Sarris, G.E., Chatzis, A.C., Giannopoulos, N.M., Kirvassilis, G., Berggren, H., Hazekamp, M., et al. (2006) The Arterial Switch Operation in Europe for Transposition of the Great Arteries: A Multi-Institutional Study from the European Congenital Heart Surgeons Association. The Journal of Thoracic and Cardiovascular Surgery, 132, 633-639. https://doi.org/10.1016/j.jtcvs.2006.01.065

[5] Frescura, C. and Thiene, G. (2016) The Spectrum of Congenital Heart Disease with Transposition of the Great Arteries from the Cardiac Registry of the University of Padua. Frontiers in Pediatrics, 4, 84. https://pubmed.ncbi.nlm.nih.gov/27713877 https://doi.org/10.3389/fped.2016.00084

[6] Yamaki, S. and Tezuka, F. (1976) Quantitative Analysis of Pulmonary Vascular Disease in Complete Transposition of the Great Arteries. Circulation, 54, 805-809. https://doi.org/10.1161/01.CIR.54.5.805

[7] Newfeld, E.A., Paul, M.H., Muster, A.J. and Idriss, F.S. (1974) Pulmonary Vascular Disease in Complete Transposition of the Great Arteries: A Study of 200 Patients. American Journal of Cardiology, 34, 75-82. https://doi.org/10.1016/0002-9149(74)90096-4

[8] Clarkson, P.M., Neutze, J.M., Wardill, J.C. and Barratt-Boyes, B.G. (1976) The Pulmonary Vascular Bed in Patients with Complete Transposition of the Great Arteries. Circulation, 53, 539-543. https://doi.org/10.1161/01.CIR.53.3.539

[9] Sharma, R., Choudhary, S.K., Bhan, A., Juneja, R., Kothari, S.S., Saxena, A., et al. (2002) Left Ventricle Is Better Suited as Pulmonary Ventricle in Simple Transposition with Severe Pulmonary Hypertension. The Annals of Thoracic Surgery, 74, 1612-1615. https://doi.org/10.1016/S0003-4975(02)03880-8

[10] Burkhart, H.M., Dearani, J.A., Williams, W.G., Puga, F.J., Mair, D.D., Ashburn, D.A., et al. (2004) Late Results of Palliative Atrial Switch for Transposition, Ventricular Septal Defect, and Pulmonary Vascular Obstructive Disease. The Annals of Thoracic Surgery, 77, 464-469. https://doi.org/10.1016/S0003-4975(03)01349-3

[11] Senning, Å. (1959) Surgical Correction of Transposition of the Great Vessels. Sur- 
gery, 45, 966-980.

[12] Jatene, A.D., Fontes, V.F., Paulista, P.P., Souza, L.C.B., Neger, F., Galantier, M., et al. (1976) Anatomic Correction of Transposition of the Great Vessels. The Journal of Thoracic and Cardiovascular Surgery, 72, 364-370. https://doi.org/10.1016/S0022-5223(19)40063-9

[13] Junge, C., Westhoff-Bleck, M., Schoof, S., Danne, F., Buchhorn, R., Seabrook, J.A., et al. (2013) Comparison of Late Results of Arterial Switch versus Atrial Switch (Mustard Procedure) Operation for Transposition of the Great Arteries. American Journal of Cardiology, 111, 1505-1509.

https://doi.org/10.1016/j.amjcard.2013.01.307

[14] Losay, J., Touchot, A., Serraf, A., Litvinova, A., Lambert, V., Piot, J.D., et al. (2001) Late Outcome after Arterial Switch Operation for Transposition of the Great Arteries. Circulation, 104, I-121-I-126. https://doi.org/10.1161/hc37t1.094716

[15] Iyer, P.U., Moreno, G.E., Caneo, L.F., Faiz, T., Shekerdemian, L.S. and Iyer, K.S. (2017) Management of Late Presentation Congenital Heart Disease. Cardiology in the Young, 27, S31-S39. https://doi.org/10.1017/S1047951117002591

[16] Penha, J.G., Zorzanelli, L., Barbosa-Lopes, A.A., Atik, E., Miana, L.A., Tanamati, C., et al. (2015) Palliative Senning in the Treatment of Congenital Heart Disease with Severe Pulmonary Hypertension. Arquivos Brasileiros de Cardiologia, 105, 353-361. https://doi.org/10.5935/abc.20150097

[17] Lindesmith, G.G., Stanton, R.E., Lurie, P.R., Takahashi, M., Tucker, B.L., Stiles, Q.R., et al. (1975) An Assessment of Mustard's Operation as a Palliative Procedure for Transposition of the Great Vessels. The Annals of Thoracic Surgery, 19, 514-520. https://doi.org/10.1016/S0003-4975(10)64425-6 